\title{
'||||||||||||||||||||||||||||||||||||||||||||||||||||||||||||||||||||.
}

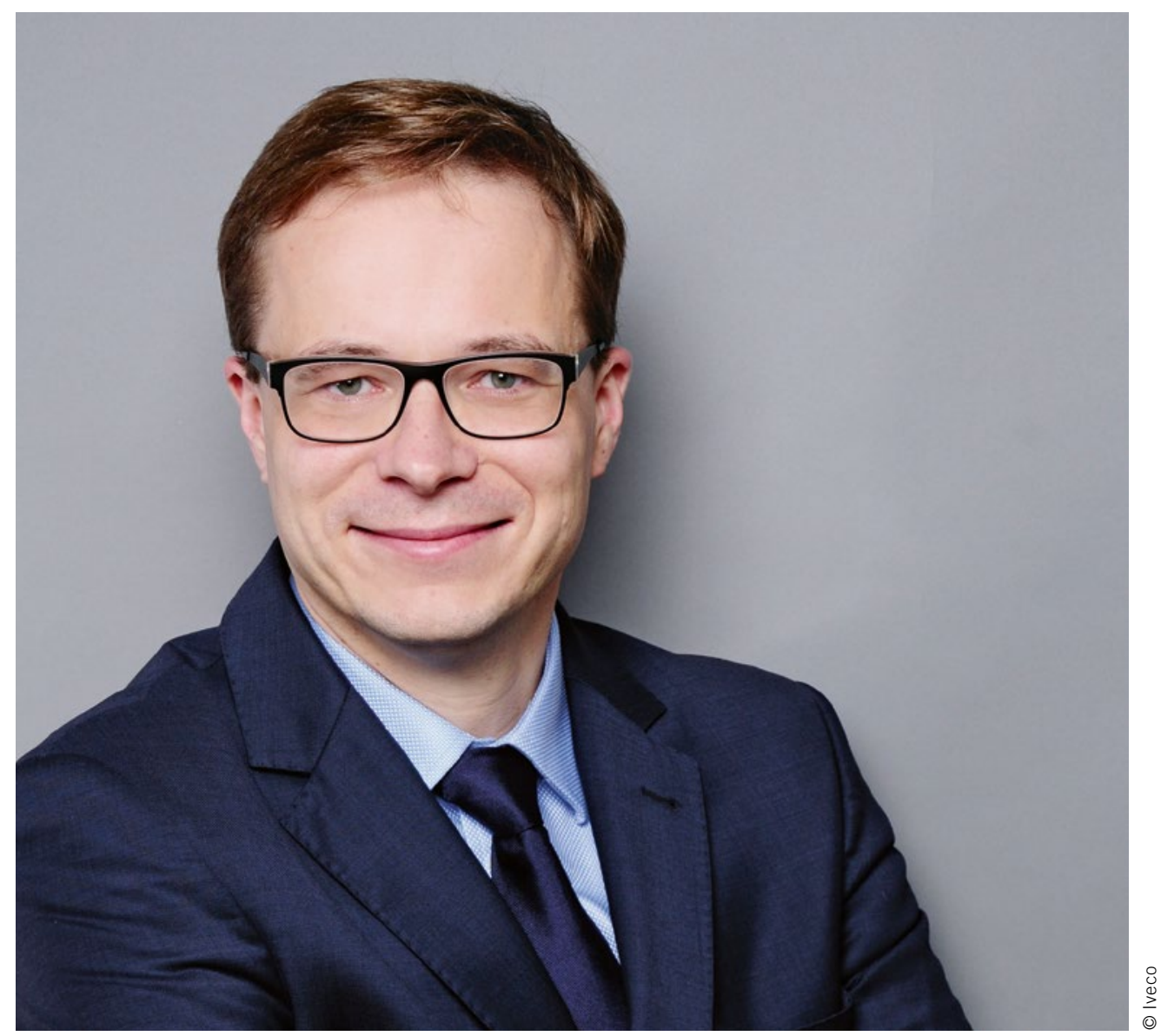

Christian Sulser

Vorstand Vertrieb und

Marketing Iveco Magirus AG

in Unterschleißheim

\section{Krise als Chance}

Die Transportbranche zeigt sich während der Corona-Pandemie als systemrelevant. Die Menschen im Umfeld der Logistik inklusive des Werkstattservices leisten wie Ärzte, Pflegepersonal, Mitarbeiter im Einzelhandel und viele andere mehr immer noch einen essenziellen Beitrag bei der Bewältigung der Krise. Die Anerkennung auch gegenüber Lkw-Fahrern ist uns nach wie vor ein Anliegen.

Wir müssen jetzt den Weg aus der Krise trotz der hohen Effizienz des Diesels auch als Chance für neue Technologien und Innovationen nutzen, ohne die Machbarkeit und das Hier und Heute zu vergessen. Beim Pkw geht der Trend zum batterieelektrischen Antrieb. Beim Lkw muss nach Anwendung unterschieden werden. Neben der Distribution in urbanen Räumen, bei der die batterieelektrische Lösung angestrebt wird, sehen wir mittelfristig die Brennstoffzelle als Lösungsweg für die Langstrecke. Dabei handelt es sich prinzipiell auch um einen elektrischen Fahrantrieb, bei dem eine Brennstoffzelle quasi als Range-Extender aufgeschaltet ist. Diese Brennstoffzelle arbeitet geräuschund emissionsfrei und verwandelt idealerweise grünen, regene- rativ erzeugten Wasserstoff über eine chemische Reaktion mit Luftsauerstoff in elektrische Energie und Wasserdampf. Damit kann man vereinfacht ausgedrückt das Nachladen der Batterie von der Steckdose auf ein mitgeführtes Kraftwerk verlegen und gewinnt Reichweite. Um keine Zeit zu verlieren, hat sich Iveco für eine Kooperation entschlossen. Als Partner war das US-Startup Nikola die erste Wahl, produziert wird im Iveco-Werk Ulm.

Die Brücke dazu ist CNG und LNG, das bereits heute als einzige Dieselalternative gilt. Mit Beimischungen von Biooder Klärgas kann man die $\mathrm{CO}_{2}$-Emissionen fast beliebig senken. Iveco ist mit Methan (Bio-/Erdgas) Fahrzeugen seit Jahren am Markt und hat die Gastechnologie als Pionier auf die Straße gebracht. Wir haben den Aufbau der LNG-Infrastruktur aktiv angestoßen und mit 35.000 verkauften Methanfahrzeugen inklusive 7000 schweren LNG-Lkw eine sehr gute Expertise. Das bedeutet nicht nur niedrige Verbräuche und geringe Emissionen, sondern auch höchste Zuverlässigkeit. Das ist für den Unternehmer eine essenzielle Voraussetzung, weil die Fahrzeuge immer Teil einer Logistikkette sind. 